\section{President}

Michael Schulder, MD Lake Success, NY, USA mschulder@northwell.edu

\section{Vice President}

Jin Woo Chang, MD, PhD

Seoul, Korea

jchang@yuhs.ac

\section{Secretary}

Konstantin Slavin, MD

Chicago, IL, USA

kslavin@uic.edu

\section{Vice Secretary}

Jean Regis, MD

Marseille, France

JeanMarie.REGIS@ap-hm.fr

\section{Treasurer}

Mojgan Hodaie, MD, MSc, FRCSC

Toronto, Canada

Mojgan.Hodaie@uhn.ca

\section{Past President}

Joachim K. Krauss, MD

Hannover, Germany

krauss.joachim@mh-hannover.de

\section{Board of Directors}

\begin{tabular}{|c|c|}
\hline $\begin{array}{l}\text { B. Abdennebi } \\
\text { A. Abosch } \\
\text { F. Al-Otaibi } \\
\text { R. Alterman } \\
\text { T. Aziz } \\
\text { J. Barcia } \\
\text { J. Bloch } \\
\text { P. Blomstedt } \\
\text { S. Chabardes } \\
\text { V. Coenen } \\
\text { Y. Comair } \\
\text { P. Doshi } \\
\text { J. Espinoza } \\
\text { E. Fonoff } \\
\text { C. Hamani } \\
\text { C. Honey } \\
\text { S. Horisawa } \\
\text { Z. Kiss } \\
\text { J. Neimet } \\
\text { B. Nuttin } \\
\text { F. Piedimonte } \\
\text { A. Rezai } \\
\text { E. Richter } \\
\text { A. Savas } \\
\text { R. Schuurman } \\
\text { A. Sitnikov } \\
\text { B. Son } \\
\text { R. Spiegelmann } \\
\text { H. Toda } \\
\text { J. Voges }\end{array}$ & $\begin{array}{l}\text { (Algeria) } \\
\text { (USA) } \\
\text { (S. Arabia) } \\
\text { (USA) } \\
\text { (UK) } \\
\text { (Madrid) } \\
\text { (Switzerland) } \\
\text { (Sweden) } \\
\text { (France) } \\
\text { (Germany) } \\
\text { (Lebanon) } \\
\text { (India) } \\
\text { (Colombia) } \\
\text { (Brazil) } \\
\text { (Canada) } \\
\text { (Canada) } \\
\text { (Japan) } \\
\text { (Canada) } \\
\text { (USA) } \\
\text { (Belgium) } \\
\text { (Argentina) } \\
\text { (USA) } \\
\text { (USA) } \\
\text { (Turkey) } \\
\text { (Holland) } \\
\text { (Russia) } \\
\text { (Korea) } \\
\text { (Israel) } \\
\text { (Japan) } \\
\text { (Germany) }\end{array}$ \\
\hline
\end{tabular}

Continental Vice-Presidents

$\begin{array}{ll}\text { D. Sakas } & \text { ESSFN } \\ \text { E. Eskandar } & \text { ASSFN } \\ \text { P. Doshi } & \text { ISSFN } \\ \text { Y. Ahn } & \text { KSSFN } \\ \text { A. Alkhani } & \text { MSSFN } \\ \text { H. Hirabayashi } & \text { JSSFN } \\ \text { J. Carillo-Ruiz } & \text { SLANFE } \\ \text { B. Sun } & \text { Mainland Asia } \\ \text { T. Coyne } & \text { Oceania/Australia } \\ \text { N. Enslin } & \text { Sub-Saharan Africa } \\ \text { A. Sitnikov } & \text { Russia }\end{array}$

\section{World Society for Stereotactic and Functional Neurosurgery}

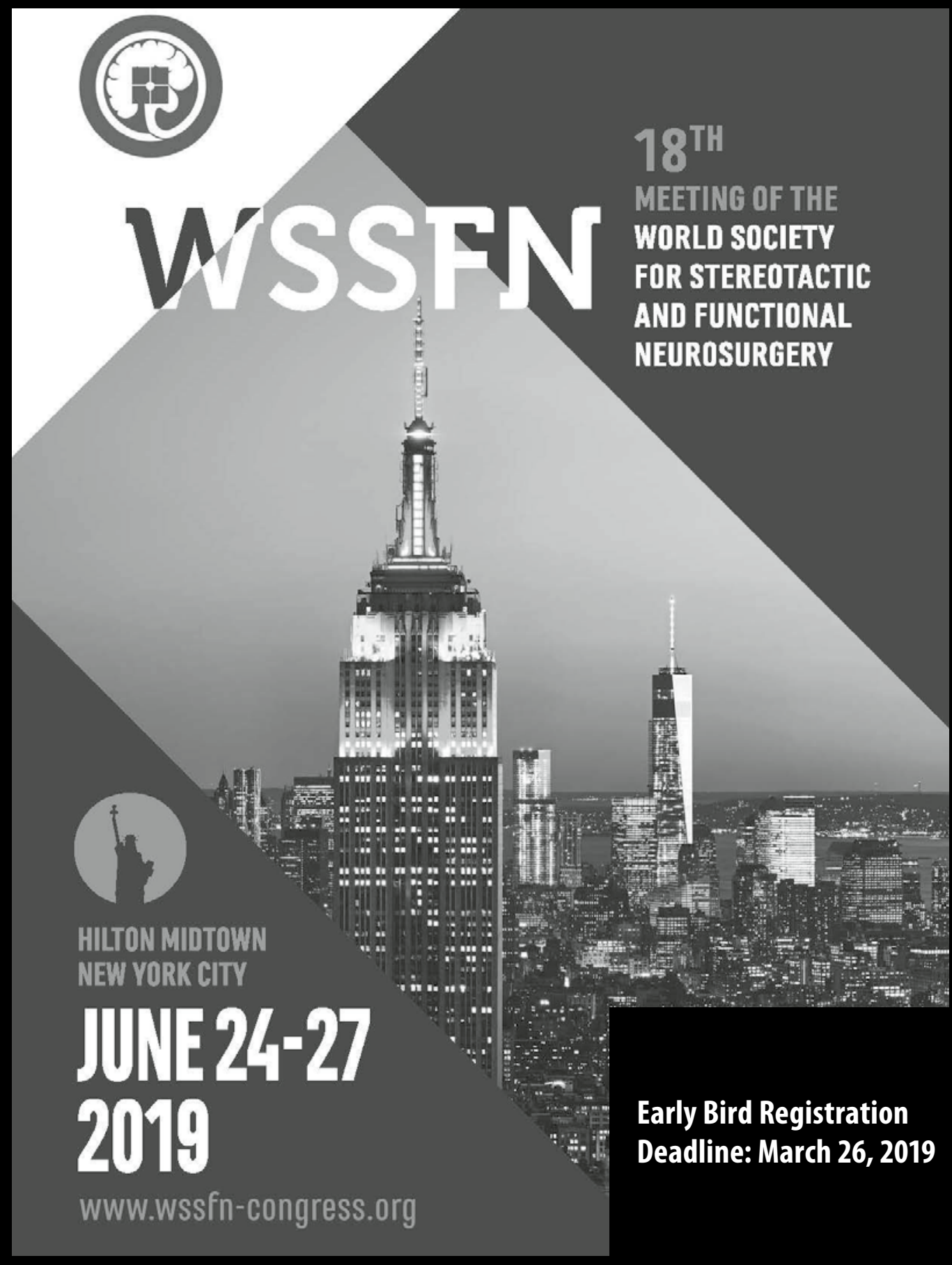

\title{
SEe You IN 2019!
}

